\title{
An Evaluation of the Effect of Instructional Methods on Student's Achievement in Technical Colleges in Akwa Ibom State
}

\author{
${ }^{1}$ Dr Nsikak-Abasi Udofia, ${ }^{2}$ Dr King Sam Ibritam, ${ }^{3}$ Dr V. E Onweh \\ ${ }^{I}$ Department of Educational Foundations, Guidance and Counselling, Faculty of Education, \\ University of Uyo, Uyo \\ ${ }^{2}$ Department of Technical Education, Akwa Ibom State College of Education AfahaNsit \\ ${ }^{3}$ Department of Vocational Education, Faculty of Education University of Uyo, Uyo
}

\begin{abstract}
The purpose of this study was to evaluate the differences in students' achievement in the construction of loadbearing walls, block-laying and concreting after they had been taught using scaffolding,demonstration, and conventional instructional methods in technical colleges in Akwa Ibom State. The study was quasiexperimental, using a sample of 90 subjects drawn through purposive random sampling technique from a population of two hundred and forty six senior technical two students offering Block-laying and Concretingin public technical colleges in Akwa Ibom State. The experimental and control groups were taught block-laying and concreting topics from NABTEB syllabus and tested by the research atendants. An instrument titled Blocklaying and Concreting Achievement Test (BCAT) was developed by the researchers and validated by three experts was used for data collection. The reliability co-efficient indices of the instrument using Cronbach's Alpha were established differently for each task of the topics taught. All the research questions were answered using the descriptive statistics; while the hypotheses were tested at .05 level of significance, using independent $t$ test and in the case of hypothesis 4, analysis of covariance (ANCOVA). The results show that: scaffolding instructional method can be used in teaching workshops-based subjects such as Block-laying and Concreting; Scaffolding instruction method has been found to be a useful teaching method for teaching Block-laying and Concreting and; Scaffolding and Demonstration Instructional Methods were found to be better teaching methods than conventional instruction method in teaching Block-laying and Concreting work. Based on the findings of this study, the researchers recommended among others, that: Technical Teachers Training Institutions should incorporate Scaffolding Instructional Method as one of the methods in their curriculum used in training and student-teachers of block-laying and concreting.
\end{abstract}

Keywords: Instructional methods, Technical education, Scaffolding, Demonstration, Block-laying, Concreting

\section{Introduction}

In vocational education, experts such as Onweh (2004) and Mbang (2008) consider the demonstration method of teaching as one of the most effective for teaching workshop-based subjects. According to them, in the demonstration method, all the necessary steps for solving a problem are covered. Also, the demonstration method provides the learners the opportunity to repeat the procedure by themselves. Demonstration method involves the senses of sight and touch, rather than the sense of hearing alone (Akpan, 2000). Most experts favour demonstration method of instruction as against other teaching methods because it involves talking, showing and questioning by the teacher and hearing, seeing, and answering by the student. The purpose of demonstration method as explained by experts is to illustrate how procedures of an operation of a task are to be carried out, in order to facilitate the learner's acquisition of the desired knowledge and skill. It involves step by step operation by the teacher; repetition by the student; assignment by the teacher and performance by the student and finally evaluation by the teacher.

Block-laying and Concreting is one of the courses offered under Building Trades in Technical Colleges in Akwa Ibom State (National Business and Technical Examination Board [NABTEB], 2007). The skill of Block-laying involves the laying of blocks using mortar as binder in a systematic manner called bonding to form the walls of a building; while the Concreting aspect requires the use of fresh Concrete (mixture of specified proportion of Cement, Gravel, Sand and Water before it hardens) to form the foundation, beam, lintel or arch, pillar and other structural part of the building that requires the use of concrete. As a course, Block-Laying and Concreting requires a result-oriented approach of instruction delivery in order to develop in the learner the needed skills for effective practice which would qualify the learner to practice or for employment and successful transition from school to industry (Emmitt \& Gorse, 2005).

Though there is clear evidence of effectiveness of Demonstration Method for skill training, it is also worthwhile to try other emerging scientific instructional methods also known to be effective in other instructional areas. Such a step could either help to further re-establish the efficacy of Demonstration Method and / or lead to the discovery of another effective method of teaching workshop-based courses. Besides, the 
approach will help to create room for comparison. It is in the light of this, that Scaffolding Instructional Method is being considered to determine its effect in the development of students' achievement in Block-Laying and Concreting task performance.

Research results as reported by McKenzie (1999); Bransford, Brown \& Cocking (2000) and Chang, Chen and Sung (2002) indicate the effectiveness of Scaffolding Instruction Method (SIM) in teaching other practical-based subjects, such as Computer Application, Mathematics, Accounting, Office Practice and Music. But there is no record of its application in Technical Education subjects such as Block-laying and Concreting.

Scaffolding Instruction Method derives its name from the practical resemblance it bears to the physical Scaffolds used on construction sites. A Scaffold as used on construction site is a temporary structure that physically supports workers while they complete jobs at higher levels that would otherwise have been impossible without its usage. A Scaffold provides workers with both a place to work and means to reach the work at higher levels that they could not have access with their own height (Herber\&Herber, 1993). Hammond (2002) described Scaffolding Instructional Method as a form of learning support provided to help learners move from their present level to higher level of knowledge. The term can also be used as an umbrella metaphor to describe the way that teachers, peers and study-mates supply students with the tools they need in order to learn (Jacob, 2001).

Scaffolding Instructional Method (SIM), therefore, is a strategy that facilitates the teaching of new knowledge or skills by engaging students collaboratively in tasks that would be too difficult for them to complete on their own. It involves the teachers initially providing extensive instructional support or scaffolding to continually assist the students in building their understanding of new concepts and procedures. Once the students have internalized or demonstrated the mastery of the contents and/or processes, they are allowed to assume full responsibility for controlling the progress of the task. The temporary scaffold or support provided by the teacher is then removed to reveal the impressive permanent structure of the student understanding of the subject of the study (Herber\&Herber, 1993).

Scaffolding Instruction involves two major steps. The first step involves the development of an instructional plan to lead the students from what they already know or from the level of the skill they have already acquired to a deep understanding of new level of knowledge and skill desired. It must be carefully written such that each bit of new information that the student needs to learn, or new skill to be acquired is based upon what the student already knows or is able to do (Lange 2002). The new level of the learnt knowledge/achievement also serves as a logical next step for further learning achievement. The teacher must prepare to continuously assess the student's learning and to add new information to the student's prior knowledge as the situation dictates (Turnbull, Turnbull, Shank \& Leal, 1999).

The second step of Scaffolding Instructional Method is execution of the plan, in which the teacher provides support to the student at every step of the learning process. At the beginning of the process, the teacher models the task in its entirety. Having observed the teacher's model, the student through guided practice, begins to perform the task and continue until he is able to perform independently (Turnbull, et al. 1999). The teacher assists the student at the beginning of the practice and continuously assesses the learning achievement. As the student gains experience with understanding of new information or tasks, the teacher increases the complexity of the activities or tasks in a guided practice. However, the teacher should be watching out for the clue of mastery and when he should gradually reduce or fade his support. By the end of the well-executed scaffolding instruction plan according to Turnbull, et. al (1999), the student embarks on performing the entire task without any support from the teacher. In other words, scaffolding is serving as a bridge used to build upon what the student already knows to arrive at something he does not know (Benson 1997). Scaffolding encourages problem-solving learning but discourages spoon-feeding instructions.

Scaffolding Instruction assumes that the learner goes to the learning situation with elements of previous knowledge on which the new knowledge must be built on. Therefore, the teacher or the More Knowledgeable Other (MKO) provides the support or scaffolding that might take the form of hints, cue or modeling, to aid the learner at the point he cannot perform further by himself. In scaffolding instructional principle, Jacob (2001) asserted that there exists a clear gap between the current knowledge level of the learner and the new level he must learn which Vygotsky (1978) called the Zone of Proximal Development (ZPD). It is only at this point (the gap) of learning that the teacher or MKO provides support or scaffolding to the learner to help him move to a higher level of learning. The function of the teacher in Scaffolding Instruction, therefore, is to facilitate learning by always being there, giving instructions, answering questions , asking questions, making useful hints or clues, provides cues and modeling to help the student acquire new knowledge or skill. The teacher must not take over the entire task completion process from the student. Rather the teacher starts the task and allows the student to complete it. He must not assume that the student is totally ignorant of the subject matter thereby spoon-feeding him with all the subject content.

In Demonstration Instruction Method, emphasis is placed on the teacher modeling the entire task for the learner to repeat the process. The practice assumes that the learner is a total novice in the subject of 
learning, which is why the teacher carries out the step by step operation of the whole task for the learner to repeat after him. Such a method of teaching, though it is perfect for skill development, appears to encourage a spoon-feeding learning tendency. There lies the difference in practice between Scaffolding and Demonstration Instruction Methods. This study, therefore, is to find out the difference in students' achievement in Block-laying and Concreting when taught using Scaffolding and Demonstration Instruction Methods.

\section{Research Question}

1. What is the difference in students' achievement in construction of load bearing walls when taught using Scaffolding and Demonstration Instructional Methods?

2. What is the difference in students' achievement in block-laying and concreting when taught using Scaffolding and Demonstration Instructional Method?

3. What is the difference in students' achievement in block-laying and concreting when taught using Demonstration and Conventional Instruction Methods?

4. What is the difference in students' achievement in block-laying and concreting after being taught using Scaffolding, Demonstration and Conventional Instruction Methods?

\section{Hypothesis}

1. There is no significant difference in the achievement of students in construction of load bearing walls when taught using Scaffolding Instructional Method and Demonstration Instructional Method.

2. There is no significant difference in the achievement of students in block-laying and concreting when taught using Scaffolding Instructional method and Demonstration Instructional Method.

3. There is no significant difference in the achievement of students in block-laying and concreting when taught using Scaffolding and Conventional Instruction Methods.

4. There is no significant difference in the achievement of students in block-laying and concreting when taught using Demonstration and Conventional and Scaffolding Instruction Methods.

\section{Research Methods}

The study adopted the quasi-experimental pretest - post-test design with non-equivalent experimental and control groups. It was aimed at evaluating the differences in students' achievement in Block-laying and Concreting after they were taught using Scaffolding, Demonstration and Conventional Instructional Methods in Technical Colleges in Akwa Ibom State.

The population of the study comprised all the 246 ST2 students in all the six public Technical Colleges in Akwa Ibom State. Three of the Technical Colleges were sampled 90 subjects were used for the study.30 from each of the three Colleges were drawn through purposive random sampling technique from the intact classes used for the study to compare their achievement in post-test. The researcher developed multiple choice achievement test called Block-laying and Concreting Achievement Test (BCAT) with four options, out of which one answer was correct. BCAT was used to determine the achievement of the Experimental Groups and that of the Control Group (see Appendix G). The BCAT covered all the selected topics on Block-laying and Concreting work of the NABTEB syllabus taught to ST2 students in the Technical Colleges in Akwa Ibom State.

All BCAT items were used for both pre-test and post-test for the study. In order to determine the number of test-items to be selected for a particular topic, the researcher took into consideration the scope of each of the units in terms of relevance to the topic taught. Units that were large in scope attracted more items than those that were small in scope. As shown in the table of specifications, questions/items that demanded application received greater attention than those at the knowledge level which merely demanded recall of facts. In all, 60 multiple choice questions were constructed to cover the scheme of work for ST2 in NABTEB syllabus for construction trades examination.

Face and content validation of the Block-laying and Concreting Achievement Test (BCAT) was carried out. For this purpose, the BCAT was given out to three experts, two from Technical Education, one from the Department of Educational Measurement and Evaluation in the University of Uyo, Uyo. Specifically the experts were requested to examine the instrument along the following criteria: clarity of the instrument and the questions, appropriateness of the instructions and questions to the students' level of understanding and experience.

Also, the experts were required to make comments which were utilized by the researcher in the improvement of instruction plans and the achievement test. Besides face and content validations, psychometric properties such as difficulty, discrimination and distraction indices, (see Appendix H) of the Achievement Test were computed to determine the internal validity of the instrument. For this purpose, the Block-laying and Concreting Achievement Test was administered on 50 Senior Technical 2 (ST2) students offering Block-laying and Concreting at Main Land Technical College, Oron, Akwa Ibom State. 
The Block-laying and Concreting Achievement Test (BCAT) was tested on 22 Senior Technical 2 (ST2) students offering Block-laying and Concreting in Union Technical College, Ikpa, in Eket Local Govt. Area of Akwa Ibom State, because they did not involved in the study. They were tested twice by the researcher with a time lag of three weeks. The Pearson Product Moment Correlation of their scores was used for computing the coefficient of reliability of the instrument. The reliability indices of the instrument using Cronbach alpha for each task was established as follows: site preparation $=0.98$; Setting out $=0.97$; Construction of Strip Foundation = 0.93; Construction of Solid Concrete Ground Floor = 0.93.

Table 1: Reliability indices of the research instrument using Cronbach's alpha

\begin{tabular}{lcccc}
\hline Variable & Number of items & $\bar{x}$ & $\sigma$ & $\mathrm{r}$ \\
\hline Site preparation & 7 & 40.51 & 0.02 & $0.98^{*}$ \\
Setting out & 8 & 40.32 & 0.08 & $0.97^{*}$ \\
Strip fundn & 8 & 40.44 & 0.04 & $0.93^{*}$ \\
Con. Floor const. & 6 & 40.44 & 0.04 & $0.93^{*}$ \\
Load Bearing wall & 9 & 40.46 & 0.02 & $0.96^{*}$ \\
Block-laying \& con. & 38 & 40.38 & 0.61 & $0.86^{*}$ \\
\hline
\end{tabular}

*Substantially high enough to justify being used for the research instrument.

The values as shown in Table 1 are substantially high and are in agreement with the opinions of some experts such as Onwioduokit (2000) and AzukaandAgomuo (2006) who stated that the reliability co-efficient of 0.05 will suffice at the early stage of an investigation. The obtained reliability co-efficient were substantially high, and were therefore, considered appropriate for the study.

Table 2: Mean Difference and Gain scores of students' achievement in the construction of load bearing walls when taught using Scaffolding and Demonstration Instructional Methods

\begin{tabular}{|c|c|c|c|c|}
\hline \multirow{3}{*}{ Treatment } & \multirow{2}{*}{\multicolumn{2}{|c|}{$\begin{array}{c}\text { Construction of Load bearing } \\
\text { Wall }\end{array}$}} & \multirow{3}{*}{ Mean Gain } & \multirow{3}{*}{ Mean Difference } \\
\hline & & & & \\
\hline & Pretest & Posttest & & \\
\hline Scaffolding instructional method & 38.40 & 53.67 & 15.27 & \multirow{2}{*}{2.44} \\
\hline Demonstration instructional method & 41.10 & 53.93 & 12.83 & \\
\hline
\end{tabular}

Data presented in Table 2 show that Scaffolding Instructional Method has scores of 38.40 and 53.67 in pre-test and post-test respectively. The corresponding figures for Demonstration Instructional Method are 41.10 and 53.93. The Mean gains of the students after they had been taught using Scaffolding Instructional Method is 15.27 and that of those taught using Demonstration is 12.83. The Mean score difference between Scaffolding Group and Demonstration Group is 2.44. Thus, the difference between the post-test Mean score of students taught using Scaffolding Instruction Method and that of those taught using Demonstration Instructional method shows that Scaffolding Instructional Method enhanced students' achievement in construction of load bearing walls more than Demonstration Instructional Method.

Table 3: Mean difference and gain scores of students' achievement in construction of load bearing wallwhen taught using scaffolding and demonstration instruction methods

\begin{tabular}{|c|c|c|c|c|}
\hline \multirow{3}{*}{ Treatment } & \multicolumn{3}{|c|}{ Construction of Load bearing } & \multirow{3}{*}{ Mean Difference } \\
\hline & \multicolumn{2}{|c|}{ Wall } & \multirow[t]{2}{*}{ Mean Gain } & \\
\hline & Pretest & Posttest & & \\
\hline Scaffolding instructional method & 38.77 & 53.93 & 15.16 & \multirow{2}{*}{1.89} \\
\hline Demonstration instructional method & 40.43 & 53.70 & 13.27 & \\
\hline
\end{tabular}

The data presented in Table 3 reveal that Scaffolding Instructional Method has scores of 38.77 and 53.93 in pretest and post-test respectively, and the corresponding figures for Demonstration Instructional Method are 40.43 and 53.70. The Mean gains of the students after they had been taught using Scaffolding Instructional Method is 15.16 and that of those taught using Demonstration is 13.27. The Mean score difference between them is 1.89. Thus, the difference between the post-test Mean score of students taught using Scaffolding Instructional Method and that of those taught using Demonstration Instructional Method means that Scaffolding Instructional Method could enhance students' achievement in construction of load bearing wallwork more than Demonstration Instructional Method. 
Table 4:Mean Difference and Gain scores of students' achievement in block-laying and concreting when taught using Scaffolding and Conventional Instruction Methods

\begin{tabular}{|c|c|c|c|c|}
\hline \multirow{3}{*}{ Treatment } & \multicolumn{3}{|c|}{ Block-laying and Concreting } & \multirow{3}{*}{ Mean Difference } \\
\hline & \multicolumn{2}{|c|}{ Work } & \multirow[t]{2}{*}{ Mean Gain } & \\
\hline & Pretest & Posttest & & \\
\hline Scaffolding instructional method & 40.43 & 53.70 & 13.27 & \multirow{2}{*}{10.61} \\
\hline Conventional instruction method & 42.37 & 45.03 & 2.66 & \\
\hline
\end{tabular}

The data presented in Table 4 show that Scaffolding Instructional Method has scores of 40.43 and 53.70 in pre-test and post-test respectively, while Conventional Instruction Method has scores of 42.37 and 45.03 in pre-test and post-test respectively. The Mean gains of the students after they had been taught using Scaffolding Instructional Method is 13.27 and that of those taught using Conventional Instruction Method is 2.66. The Mean score difference between students taught using Scaffolding Instructional Method and those taught using Conventional Instruction Methods is 10.61. The difference between the post test scores of the students taught using Scaffolding Instructional Method and those taught using Conventional Instruction Method indicates that Scaffolding Instructional Method is capable of enhancing achievement of students more than Conventional Instruction Methods in block laying and concreting work.

Table 5: Mean Difference and Gain scores of students' achievement in block-laying and concreting when taught using Scaffolding, Demonstration and Conventional Instruction Methods

\begin{tabular}{|c|c|c|c|c|}
\hline \multirow[t]{2}{*}{ Treatment } & \multicolumn{2}{|c|}{$\begin{array}{l}\text { Block- laying and } \\
\text { Concreting Work }\end{array}$} & \multirow[t]{2}{*}{ Mean Gain } & \multirow[t]{2}{*}{ Mean Difference } \\
\hline & Pretest & Posttest & & \\
\hline Scaffolding instructional method (T1) & 38.77 & 53.93 & 15.16 & $1.89(\mathrm{~T} 1-\mathrm{T} 2)$ \\
\hline Demonstration instructional method (T2) & 40.43 & 53.70 & 13.27 & $12.50(\mathrm{~T} 1-\mathrm{T} 3)$ \\
\hline Conventional instruction method (T3) & 42.37 & 45.03 & 2.66 & $10.61(\mathrm{~T} 2-\mathrm{T} 3)$ \\
\hline
\end{tabular}

Table 5 shows that Demonstration Instructional Method has scores of 40.43 and 53.70 in pretest and post-test respectively, while the corresponding figures for Conventional (lecture) Instruction Method are 42.37 and 45.03. The Mean gains of the students after they had been taught using Demonstration Instructional Method is 13.27 and that of those taught using Conventional Instruction (lecture) methods is 2.66. The Mean score difference between Demonstration and Conventional Instruction Methods is 10.61. It follows that there is a difference between the post-test Mean scores of students taught using Demonstration Instructional Method than that of those taught using Conventional Instruction Method. It means that Demonstration Instructional Method enhances students' achievement in block-laying and concreting work more than Conventional Instruction Method.

It has already been established in Tables 5 that Scaffolding Instructional Method enhanced students' mean achievement in Block-laying and concreting more than Conventional Instructional Method.

Table 6: Independent t-test of the difference in the achievement of students in construction of load bearing walls taught using Scaffolding Instructional Method and Demonstration Instructional Method

\begin{tabular}{lcccc}
\hline Variables & $\mathrm{n}$ & $\bar{x}$ & SD & t-cal \\
\hline Scaffolding & 30 & 53.67 & 11.67 & \multirow{2}{*}{0.09} \\
Demonstration & 30 & 53.93 & 11.70 & \\
\hline
\end{tabular}

t-cal not significant at .05 level; $\mathrm{df}=58$; critical $\mathrm{t}-$ value $=2.02$

Data presented in Table 6 indicate that the calculated t-value 0.09 is less than the critical t-value at $\mathrm{df}$ 58 which is 2.02 at .05 significant level, hence the null hypothesis is retained. There is no significant difference in the mean achievement of students' scores taught using Scaffolding Instructional Method and that of those taught using Demonstration Instructional Method.

Table 7: Independent t-test of the difference in the achievement of students in Block-laying and concreting when taught using Scaffolding Instructional Method and Demonstration Instructional Method

\begin{tabular}{lcccc}
\hline Variables & $\mathrm{n}$ & $\bar{x}$ & SD & t-cal \\
\hline Scaffolding & 30 & 53.93 & 11.53 & \multirow{2}{*}{0.08} \\
Demonstration & 30 & 53.70 & 11.72 & \\
\hline
\end{tabular}

$\mathrm{t}$-cal not significant at .05 level; $\mathrm{df}=58$; critical $\mathrm{t}$ - value $=2.02$

Data presented in Table 7 show that the calculated t-value 0.08 is less than the critical t-value at df 58 which is 2.02 at .05 significant level, hence the null hypothesis is retained. There is no significant difference in 
the mean achievement of students' scores taught using Scaffolding Instructional Method and that of those taught using Demonstration Instruction Method in Block-laying and Concreting.

Table 8: Independent t-test of the difference in the achievement of students in Block-laying and concreting when taught using Scaffolding Instructional Method and Conventional Instruction Methods

\begin{tabular}{lcccc}
\hline Variables & $\mathrm{n}$ & $\bar{x}$ & SD & $\mathrm{t}$-cal \\
\hline Scaffolding & 30 & 53.93 & 11.53 & \multirow{2}{*}{$3.14^{*}$} \\
Conventional & 30 & 45.03 & 10.41 & \\
\hline
\end{tabular}

* Significant at .05 level $\mathrm{df}=58$; critical $\mathrm{t}$ - value $=2.02$

Data presented in Table 8 show that the calculated $t$-value 3.14 is greater than critical $t$-value at df 58 which is 2.02 at .05 significant level, hence the null hypothesis is not retained. There is significant difference in the Mean achievement scores of students taught using Scaffolding Instructional Method and that of those taught using Conventional Instruction Method in block laying and concreting.

Table 9: One way analysis of covariance of difference in the achievement of students in Block-Laying and Concreting when taught using Scaffolding, Demonstration and Conventional Instruction Methods

\begin{tabular}{lllll}
\hline Group & $\mathrm{n}$ & $\bar{x}$ & \multicolumn{1}{c}{ SD } \\
\cline { 1 - 4 } Scaffolding & 30 & 53.93 & 11.53 & \\
Demonstration & 30 & 53.70 & 11.71 \\
Conventional & 30 & 45.03 & 10.41 & \\
Total & 90 & 50.89 & 11.86 & \\
\hline Source of variation & Sum of square & df & Mean square & F-cal \\
\hline Group & 22080.89 & 2 & 1040.45 & $10.89^{*}$ \\
Error & 8312.66 & 87 & 95.54 & \\
Total & 30393.55 & 89 & & \\
\hline
\end{tabular}

* Significant at .05 level; $\mathrm{df}=87$; critical F- value $=$ concrete $(87: 2)$

Data presented in Table 9 indicate that calculated F-value 10.89 is greater than critical F-values at $\mathrm{df} 2$ and 87 which is $87: 2$ at .05 significant level, hence the null hypothesis is rejected. There is significant difference in the mean achievement scores of students when taught using Scaffolding, Demonstration and Conventional Instruction Methods. Based on the significance of the result, it was necessary to prepare post hoc test in order to determine the group between which the significant difference lied in Table 9.

Table 10: Post Hoc Test (least significant difference) ofdifference in the achievement of students in blocklaying and concreting after being taught using Scaffolding, Demonstration and Conventional Instruction

\begin{tabular}{lllll}
\multicolumn{5}{c}{ Methods } \\
\hline (A) GROUP & (B) GROUP & Mean Difference (A-B) & Std. Error & Sig. \\
\hline Scaffolding & Demonstration & .233 & 2.90 & .94 \\
Demonstration & Scaffolding & -.233 & 2.90 & .94 \\
& Conventional & $8.67^{*}$ & 2.90 & .004 \\
Conventional & Scaffolding & $-8.90^{*}$ & 2.90 & .003 \\
\hline
\end{tabular}

The post hoc test shown in Table 10 reveals that the significant differences lie between Scaffolding and Conventional Methods (8.90) and between Demonstration and Conventional Methods (8.67), with the least significant difference lying between Scaffolding and Demonstration Methods (.233). The mean difference between Scaffolding and Demonstration is .233 and is less than .94 critical values; hence the less significant lie between Scaffolding and Demonstration methods.

\section{Discussion of Findings}

The result of data analyses in Table 2 with respect to the difference in students' achievement in construction of load bearing walls after they had been taught using Scaffolding and Demonstration Instructional Methods showed that the null hypothesis was retained. This implies that there was no significant difference in the mean achievement of students taught using Scaffolding Instructional Method and those taught using Demonstration Instructional Method. This result means that both Scaffolding and Demonstration Instructional Method are viable and equally effective methods of teaching that could be used for teaching construction of load bearing walls for an improved achievement.

However, the findings as shown in Table 3 indicated that scaffolding Instructional Method had a higher mean achievement score in students post-test. This means that Scaffolding Instructional Method enhanced students' Mean achievement in teaching construction of load bearing walls more than Demonstration Instructional Method. 
The result of data presented in Table 3 indicated that students taught using SIM in all the selected topics in block-laying and concreting had slight differences from those taught using DIM in mean achievements. The difference was quite marginal, indicating that the two teaching method can compare fairly well. The t-test result as presented in Table 7 also indicated that there was no significant difference in the mean achievement scores of students taught using Scaffolding Instructional Method and that of those taught using Demonstration Instructional Method in Block-laying and Concreting work.

The result of study as shown in Table 4 indicated that students taught using Scaffolding Instructional Method had higher posttest mean achievement score in block-laying and concreting than those taught using conventional method. The t-test value analyses as presented in Table 8 shows statistically significant difference between Scaffolding and Conventional Instruction Methods.

The implication of this finding is that Scaffolding Instructional Method is far more effective in teaching practical based subject such as block-laying and concreting than Conventional Instruction Method. This finding corroborates with the findings of Lipscomb, Swanson and West (2004) in emerging perspective on learning in teaching and technology, who all observed that Scaffolding Instructional Method supports students to perfect learning performance.

The analyses of the data for answering Research Question 4 which sought to find out the difference in students mean achievement in block-laying and concreting after they had been taught using Scaffolding, Demonstration and Conventional Instruction Methods revealed a wide margin in the performance of students taught using Demonstration and Conventional Instruction Methods. Data in Table 5 has already shown that Scaffolding Instructional Method enhanced better achievement than Conventional Method. This implies that both Scaffolding and Demonstration Instruction Methods are far more effective for teaching block-laying and concreting subjects than Conventional Instruction Method.

Analyses of Covariance (ANCOVA) results of students taught using Scaffolding, Demonstration and Conventional Instructional Methods indicated significant difference in the mean achievement of the students (see Table 9). However, the post Hoc test shown in Table 10 reveals that the significance occurred between Scaffolding and Conventional; between Demonstration and Conventional, with the least significance occurrence between Scaffolding and Demonstration Instructional Methods. The implication of the result of the analyses is that scaffolding and Demonstration Instructional methods are closely related in terms of effectiveness as teaching methods for workshop-based instructions and that, conventional (Lecture) method alone should not be used for teaching workshop- based subjects. Although Scaffolding Instructional Method has appeared to show slight superiority over Demonstration Instructional Method, it should not be used alone. The two methods should be applied interchangeably or be combined for greater achievement.

The findings from the result of this study have far-reaching implications to Technical Colleges; Technical School Board; the Ministry of Education and other institutions involved in provision of Block-laying and Concreting Education, institutions involved in training teachers of Block-laying and Concreting, studentteachers trained to teach Block-laying and Concreting.

Scaffolding Instructional Method was found to have enhanced students' achievement in all the tasks in Block-laying and Concreting which implies that SIM is a powerful instructional method which could be used either alone or combined with DIM in teaching block-laying and Concreting work and other workshop-based instructions in Technical colleges. Since SIM has been found useful in teaching Block-laying and Concreting work, Colleges of Education would develop curriculum for Technical Teachers Training to incorporate scaffolding Instructional Method.

\section{Implications of the Study to Technical Education}

The findings from the result of this study have far-reaching implications to Technical Colleges; Technical School Board; the Ministry of Education and other institutions involved in provision of Block-laying and Concreting Education, institutions involved in training teachers of Block-laying and Concreting, studentteachers trained to teach Block-laying and Concreting.

Scaffolding Instructional Method was found to have enhanced students' achievement in all the tasks in Block-laying and Concreting which implies that SIM is a powerful instructional method which could be used either alone or combined with DIM in teaching block-laying and Concreting work and other workshop-based instructions in Technical colleges. Since SIM has been found useful in teaching Block-laying and Concreting work, Colleges of Education would develop curriculum for Technical Teachers Training to incorporate scaffolding Instructional Method.Technical Teacher Training Institutions should incorporate Scaffolding Instructional Method along with Demonstration Instructional Method as a teaching method taught to the student teachers of Block-laying and Concreting. 


\section{References}

[1]. Akpan, G. A. (2000). Instructional Techniques Preferences for Teaching Essential Work Skills in Technical Education.International Journal of Educational Development, 3 (2):54 - 59.

[2]. Akwa Ibom State Technical School Board.(2011). Students Enrollment - Senior Technical 2 Block-Laying and Concreting. Uyo: Akwa Ibom State Technical School Board

[3]. Azuka, E. B., \&Agomuo, E. E. (2006).Research Techniques for Tertiary Institutions.Oko: Dataword Computers Academy.

[4]. Benson, B. (1997). Scaffolding: Coming to terms. English Journal, 86 (7): $126 \quad-\quad 127 . \quad$ Retrieved from http://project.coe.uga.edu/index.php?title=Scaffolding on July 6,2010.

[5]. Bransford, J., Brown, A., \& Cocking, R. (2000). How People Learn: Brain, Mind, Experience and School. Washington, DC: National Academy press.

[6]. Chang, K., Chen, I., \& Sung, Y. (2002). Effect of Concept Mapping to Enhance Text Comprehension and Summarization.The Journal of Experimental Education, 71 (1): 5 - 23.

[7]. Emmitt, S., \& Gorse, C (2005).Barry's Introduction to Construction of Buildings. Malden, MA: Blackwell Publishing Ltd.

[8]. Hammond, J. (2002). Scaffolding and Learning in Language and Literacy Education. New Town, Australia: PETA.

[9]. Herber, H., \&Herber, J. (1993).Teaching in Content Areas with Reading, Writing and Reasoning.Allyn\& Bacon: Needham Heights, M.A.

[10]. Ibritam, K. S. (2007). Fundamental of Building Practice. Ibadan: Panse Press Limited.

[11]. Jacob, G. (2001). Providing the Scaffolding: A Model for Early Childhood/Primary Teacher Preparation.Early Childhood Education Journal, 29 (2): 45 - 48.

[12]. Lange,V.I.(2002) Instructional Scaffolding. Retrieved from http://condor.Admin.Cuny.Edu/-qroup 4/cano/cano\% 20 paper. Doc on July 6, 2010.

[13]. Lipscomb, L., Swanson, J. \& West, A. (2004).Emerging Perspective on Learning, Teaching and Technology.In M. Orey (Ed.).University of Georgia.Retrieved from http://project.coe.uga.edu/epltt/index.php?title=scaflding on July 6, 2010.

[14]. Mbang, C. O. (2008). Instructional Methods, Students' Characteristics and Psychomotor Performance in Basic Electricity in Cross Rivers State.Unpublished M.Sc. Dissertation, University of Uyo, Uyo.

[15]. Mckenzie, J. (1999). Scaffolding for Success: BeyondTechnology, Questioning, Research and Information Literate School Community. (Retrieved from "http://fno.org/dec 99/Scaffol. Intnl on April 28, 2011.

[16]. National Business and Technical Examinations Board [NABTEB]. (2007). Syllabuses for Construction Trades Examinations. Benin City.

[17]. Onwioduokit, F. A. (2000). Educational Research Methodology and Statistics. Uyo: Dorand Publishers.

[18]. Onweh, V. E. (2004). Instructional Design for the Practical Component of Building Technology for the Nigerian Certificate in Education.Unpublished PhD Thesis University of Nigeria, Nsukka.

[19]. Turnbull, A., Turnbull, R., Shank, M., \& Leal, D. (1999). Exceptional Lives: Special Education in Today's Schools. Prentice-Hall, Inc: Upper Saddle River. NJ.

[20]. Vygotsky, L. S. (1978). Mind in Society. Cambridge, M. A.: Harvard University Press. http://www.aare.edu.au/03pap/ver03682.pdf. Retrieved on 28/04/2011. 